\title{
NICANOR PARRA: LA CUECA SOLA DE "EL HOMBRE IMAGINARIO"
}

\author{
Mario Rodríguez Fernández \\ Universidad de Concepción \\ mariorod@udec.cl
}

RESUMEN / ABSTRACT

Este hermoso poema se construye en el nivel morfológico mediante el sustantivo "corazón" y el verbo brindar. Ambos lexemas son los únicos en el texto que no están determinados por el adjetivo imaginario. Al no serlo, por inferencia se puede llegar a la conclusión de que son una referencia "real". Real en el sentido que el sujeto no puede eliminar el deseo, que de acuerdo a Deleuze, "crea lo real". Freudianamente en el poema podría verse el fantasma de la carencia, o por el contrario, antiepidicamente, la realidad del deseo.

Por último y tal vez lo más sugerente, una observación hecha por el poeta Leonardo Sanhueza me encamina a postular que en el poema hay una cueca encriptada, específicamente, la "cueca sola".

PALABRAS CLAVE: corazón, deseo, fantasma y cueca.

This beautiful poem is built on the morphological level by the noun "heart" and the verb offer. Both lexemes are the only ones in the text that are not determined by the adjective 'imaginary'-How they are not, by inference can conclude that they are a "real" reference. Real in the sense that the subject can not eliminate the desire, according to Deleuze, "make the real". In the Freudian way, in the poem might be the ghost of lack, or conversely, antiedipicly, the reality of desire. Finally, an observation by the poet Leonardo Sanhueza directs me to postulate that in the poem there is a encrypted cueca, specifically the "alone cueca".

KEY WORDS: heart, desire, phantom, cueca. 
"El hombre imaginario" es uno de los textos más célebres de Nicanor Parra. En El Mercurio el crítico Ignacio Valente, califica de excepcional el poema, tanto por su calidad como también por su estilo dentro de la obra de Parra, "puesto que no contiene acento alguno de ironía, ni de crítica de la vida, ni idioma coloquial, ni los demás integrantes que han dado en llamarse antipoesía" (El Mercurio, 7 de julio 1991).

\author{
El Hombre Imaginario \\ El hombre imaginario \\ vive en una mansión imaginaria \\ rodeada de árboles imaginarios \\ a la orilla de un río imaginario \\ De los muros que son imaginarios \\ penden antiguos cuadros imaginarios \\ irreparables grietas imaginarias \\ que representan hechos imaginarios \\ ocurridos en mundos imaginarios \\ en lugares y tiempos imaginarios \\ Todas las tardes tardes imaginarias \\ sube las escaleras imaginarias \\ y se asoma al balcón imaginario \\ a mirar el paisaje imaginario \\ que consiste en un valle imaginario \\ circundado de cerros imaginarios \\ Sombras imaginarias \\ vienen por el camino imaginario \\ entonando canciones imaginarias \\ a la muerte del sol imaginario \\ $\mathrm{Y}$ en las noches de luna imaginaria \\ sueña con la mujer imaginaria \\ que le brindó su amor imaginario \\ vuelve a sentir ese mismo dolor \\ ese mismo placer imaginario \\ y vuelve a palpitar \\ el corazón del hombre imaginario
}

(Parra 2011: 272 )

Se trata de un poema eminentemente descriptivo compuesto por cinco estrofas de forma irregular (de cuatro versos, de seis y de siete), construido sobre la figura retórica de la reiteración de un solo adjetivo. La reiteración 
da origen a repetidos paralelismos que producen una estructura espacial del texto. Son, precisamente, las relaciones espaciales las que le confieren su organización. Las relaciones causales no están claramente presentes y las temporales funcionan una sola vez. Espacialmente el texto se organiza como un mirador, un alto lugar desde el cual el sujeto observa y recuerda. Esta última determinación verbal es particularmente importante. Temporalmente todos los verbos del poema están en tiempo presente: vive, son, penden, sube, asoma, etc.; excepto un verbo que está en pretérito definido: "brindó". Sugerente forma verbal en cuanto se refiere al complemento directo "su amor". Más "apropiado" habría sido decir que le dio, le entregó, su amor. Brindar el amor presupone una forma muy especial del sentimiento. Naturalmente, implica el brindis, acto social en que después de beber el vino o el licor se manifiesta el bien que se desea.

El amor de la mujer imaginaria fue, entonces, una entrega sentimental signada por la alegría y el deseo de felicidad que hizo latir ardientemente el corazón del hombre imaginario. Ida la mujer, el corazón se enfrió, atenuó sus latidos. Ya no hubo placer ni dolor en su movimiento. Por ello, en las cuatro primeras estrofas domina una perspectiva impersonal. Se describe el lugar en que habita el sujeto y la vida que lleva impersonalmente, sin aludir jamás a sus sentimientos. El hombre imaginario, recurriendo a una figura amada por Parra, parece un monje taoísta; un sujeto capaz de dominar todos sus deseos. Nada se sabe de lo que piensa y siente en su soledad o cuando se asoma al balcón a mirar y escucha los cantos de las sombras que vienen por el camino. A pesar de que estas situaciones invitan a la efusividad sentimental, no hay ninguna expresión de dolor del personaje. Esa actitud de dominio sobre sí mismo no excluye algunos indicios que califican el deterioro del ambiente que lo rodea. Estrictamente son dos los adjetivos calificativos en esta línea, el referido a los cuadros, "antiguos", y a grietas, "irreparables". Nada se predica de los árboles, del río, del valle, de los cerros, del camino, del sol y la luna, excepto, que según la lógica del poema, son imaginarios.

La antigüedad de los cuadros, que son como irreparables grietas de los muros o se confunden con ellas, creo que connota la imposibilidad de recuperar el pasado, de reconstruir el amor perdido. Hay pocos sentimientos tan desgarradores como esos, los de constatar que lo que se perdió, se dejó o abandonó ya no es posible volver a tenerlo. Hay dos posibilidades frente a este drama, opuestas ciertamente, entregarse al dolor más desenfrenado hasta hacer estallar el corazón, o aquietar sus latidos al mínimo, como recomienda el taoísmo y dejar pasar por encima la terrible tormenta, lo que Deleuze 
llama filosóficamente las "fuerzas del afuera", que a la luz del poema de Parra, imagino como un muro debilitado para siempre, hasta la muerte, por una irreparable grieta.

No se puede dejar de ver en el poema bajo la maravilla retórica de la reiteración (la retórica puede llegar a ser también maravillosa si se emplea con la maestría de Parra) una experiencia hondísima del dolor ocasionado por la mujer perdida. Experiencia compartida por muchos lectores, que el poeta les invita imaginar.

El dolor se acrecienta en la última estrofa cuando el corazón vuelve a latir ardorosamente. En el sueño vuelve el sujeto a sentir el mismo dolor y placer. La fuerza ardiente del corazón ha derrotado la frialdad defensiva del monje taoísta: "y vuelve a palpitar el corazón del hombre imaginario".

Reparemos que el palpitar no solo produce dolor, sino también placer. Lo último se explica por las connotaciones de "brindis": el deseo placentero del amor "brindado".

Pareciera que el sustantivo corazón y el verbo brindar fueran los dos ejes semánticos en torno a los cuales se construye el poema. Significativamente, el primero, "corazón", no lleva el calificativo imaginario, a menos que se demuestre lo contrario y es el único caso del texto que carece de ese adjetivo. Imaginario, en el verso que se refiere al corazón, recae sobre el sustantivo hombre ("y vuelve a palpitar el corazón del hombre imaginario"); en el caso de brindó, la diferencia reside en que es el único verbo en pretérito de la serie verbal ("que le brindó su amor imaginario"), ya que los demás modos siempre están en presente.

Si el sustantivo no es imaginario, por inferencia tendría que ser "real". "Real" en el sentido que toda la espléndida arquitectura del poema, del poema-mirador, es incapaz de apaciguar el deseo, que como el poder crea la realidad. A pesar de que el deseo del hombre solitario parece estar dominado y muerto, reaparece en el sueño, ese temible lugar donde el deseo adquiere formas fantásticas negándose a morir. Si el deseo crea lo real, como manifiestan Deleuze y Guattari, en Antiedipo el corazón y el verbo brindar son los únicos entes "reales" del poema.

En una suerte de quiasmo, el texto se construye sobre el corazón apagado que proporciona indiferencia imaginaria y el corazón encendido que brinda dolor y placer reales. En las cuatro primeras estrofas domina el corazón que no late ni con el placer ni con dolor, en la última, se produce la torsión a partir del sueño. La mujer reaparece en él desenterrando los sentimientos congelados y abriendo una escena de amor no dicha hasta el momento. 
Escena de pérdida que permite releer los versos anteriores desde una nueva perspectiva: la de la derrota del olvido, de la tentativa de enfriar el amor, lo que en dos palabras significa el triunfo del deseo.

El retorno y victoria del deseo se producen en el inconsciente. Freudianamente podría verse en el poema su escenificación. El fantasma de la carencia se aparece en el sueño y se pasea por él como un personaje se mueve en las tablas teatrales. "El hombre imaginario" sería la representación teatralizada del fantasma. Pero contrariamente, el texto puede también apuntar al inconsciente como una "fábrica" productora del deseo, no como un teatro donde pasea el fantasma de la mujer, porque ya sabemos que el deseo produce lo real, no la ausencia. Las posibilidades son dos, nada más que dos en este caso: "El hombre imaginario" como poema del fantasma, o "El hombre imaginario" como poema de la realidad del deseo.

La repetición del vocablo imaginario, entendido en uno de sus sentidos, inclinaría a pensar que se trata del fantasma, de lo que carece de sustancia, mejor dicho, de aquello cuya única "sustancia" es la carencia. Según el análisis expuesto, el deseo reparte sus roles entre el del fantasma, y el de producir lo real. Me parece mucho más atractiva que esta oposición el diseño poético del "entre"; entre el fantasma y la realidad del deseo. Además, de atractivo, es propio del genio creativo del antipoeta.

A pesar de que es muy fácil conectar fantasma con lo imaginario y mucho más dificultoso es hacerlo con lo real, se puede decir que "El hombre imaginario", como título y personaje lírico, representan la realidad del deseo, lo que significa que en el espacio lírico Parra nos propone que el hombre imaginario es el hombre real, lo que implica su anverso: todo hombre real es imaginario. Fulminadas caen las oposiciones. La cara de lo imaginario es parte sustantivo de lo real y viceversa. Así, el mundo se presenta como es: hibridez, mezclas y contagio.

Esta conclusión, en un sujeto siempre está incriptado otro, me induce a otro acercamiento al poema, tal vez más sorprendente que el anterior. Esta apertura a un nuevo sentido del poema se produce puntualmente a partir de una observación hecha por el poeta Leonardo Sanhueza a los autores de las "Notas" de las Obras completas \& algo +: "a partir de la segunda estrofa es predominante la forma métrica de la seguidilla, que es la forma básica de la cueca, es decir, heptasílabo + pentasílabo (imaginario). El resultado es muy curioso, porque usa un metro de arte menor pero logra un efecto de arte mayor con endecasílabos o dodecasílabos cuya censura fluye de manera natural" 
(Parra 2011: 1054). Según la sugerencia habría que disponer métricamente el texto, a partir de la segunda estrofa, de la siguiente manera:

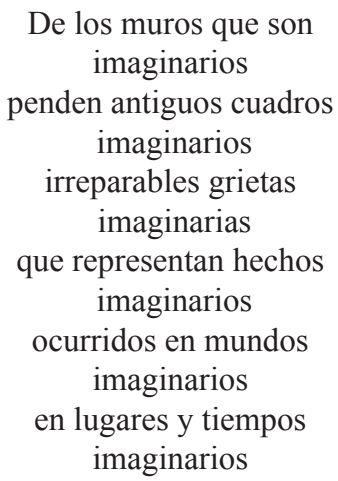

Y así sucesivamente, mostrando la combinación propiamente tal de la seguidilla. Para mostrar su existencia añado un elemento más de justificación.

En la tercera estrofa el verso inicial presenta la repetición del sustantivo "tardes": "todas las tardes tardes imaginarias", sin otra razón aparente que no sea la de la necesidad métrica. Para conseguir que el heptasílabo no le quede cojo, el autor se ve obligado a la repetición, en lo que sigue el molde rítmico de la cueca: "para llegar a las siete sílabas se le añaden normalmente las palabras "si", "no", "mi alma" u otro bisílabo a criterio del cantor" (Binss 2011: 930).

Luego, Parra usa la repetición de "tardes" como si fuera un "si", un "no" o un "ay", muy frecuente también en la composición métrica de la cueca.

A raíz de ello, me permito proponer que disimulada en este bello poema de amor, hay una cueca, una cueca encriptada.

Que la haya no es un hecho inesperado en la producción antipoética. A partir de 1958, con la publicación de La cueca larga, editada por Editorial Universitaria con ilustraciones de Nemesio Antúnez, queda patente la inclinación que siempre ha mostrado el hermano de Violeta por las formas de la música popular. A propósito de ello, escribe Jorge Edwards en Diálogos en un tejado: "Violeta había comenzado como cantante popular en el sentido más bien comercial del término, hasta que decidió buscar en el campo, entre viejos cantores y cantoras las raíces de lo que se llamaba por tierras de Chillán adentro, hacia la cordillera, canciones a lo humano y a lo divino, profanas y religiosas. Así encontró formas musicales originales, que después llegaron a 
todas partes, en esa búsqueda de un pasado remoto, de una especie de Edad Media que todavía persistía en el Sur de Chile. La llegada de Nicanor al Martín Fierro y a la poesía popular es paralela, producto de la cercanía y el constante cambio de impresiones con sus hermanos Violeta y Roberto. Me acuerdo de largas sesiones en la casa de Nicanor, a comienzos de la década del cincuenta, en las que un anciano cantor popular interpretaba en su guitarrón, con el estímulo de un vaso de vino pipeño, versos a lo hermano sobre el banquete del rey Nabucodonosor. Era los temas medievales de la danza y la abundancia inagotables, el de Jauja, el de la ciudad de los Césares en la imaginación colonial chilena. Poemas como La cueca larga, que rompieron con la línea de vanguardia que llevaba la poesía de Nicanor hasta esa etapa, derivaron, en parte de aquellas sesiones, de aquella atmósfera (Edwards 2003: 63-64).

El propio Nicanor Parra recuerda que su hermana "grabó varias canciones al comienzo con letra de él. Por ejemplo, la primera canción con letra mía que ella grabó ..."Cuando salí de Chillán / salí sin ningún motivo, / salí a recorrer el mundo / porque ese era mi destino, / porque ese era mi destino. / Fue mi destino ay sí, / fue mi destino". La letra es mía, la música es de ella. Después yo publico La cueca larga. Yo estaba trabajando ya en darle forma al contrapunto, y además, tenía en proyecto en ese tiempo un libro que nunca aterrizó, que se llamaba Tonadas y cuecas" (Morales 1990:169).

Unos pocos años después, Violeta Parra grabó "la cueca de los poetas" (1966), también con letra de Nicanor.

Niall Binns, quien asesoró la edición de Obras completas \& algo +, comenta "que la inclinación natural de Nicanor Parra por la música y el lenguaje popular, patente ya -aunque de otro modo-desde Cancionero sin nombre, iba todavía a concretarse y renovarse en textos como Coplas de Navidad (antivillancico) de 1983. En relación con esta tendencia perseverante de un modo u otro a lo largo de toda la obra de Parra, lo que se entiende comúnmente por antipoesía constituye una búsqueda paralela de reconciliación entre la palabra poética y el habla común" (Binns 2006: 937).

Yo mismo (y excusen la autocitación) publiqué un artículo en la Revista Chilena de Literatura, "El bolero y la cueca"; "dos metonimias de Pablo Neruda y Nicanor Parra", en el que metafóricamente propongo que Parra "escobilla" y "zapatea" la gramática de la poesía chilena moderna, basándome en los dos pasos básicos de la cueca, el escobillado y el zapateo, al que habría que añadir un tercero: "a la tripa pollo". 
El "escobillado" se refiere a un paso (o pasito) como barriendo el suelo que ejecutan los bailarines en la primera parte de la cueca. El "zapateo" aparece en la tercera y última parte del baile y en ella el hombre zapatea de punta y taco mirando constantemente a su pareja. "A la tripa pollo" es una aceleración frenética del zapateo tanto del hombre como la mujer. En la parte final de La cueca larga, aparece inscrita al margen esa indicación.

Todos estos antecedentes justifican, supongo, la presencia de la cueca encriptada en "El hombre imaginario".

A la métrica, como el limpio pentasílabo de "imaginario" (solo comparable en este contexto a las precisas cinco sílabas de los nombres de Pablo Neruda y Nicanor Parra en "La cueca de los poetas") a las repeticiones que completan el metro elegido, puedo añadir un tercer elemento que ya no corresponde al nivel fonológico del poema, sino al semántico, y por lo tanto mucho más difícil de probar en cuanto se refiere al plano de las significaciones.

Aún más, este tercer rasgo solo aparece cuando ponemos el poema en relación con su contexto, tanto privado como público, en una suerte de análisis pragmático del texto, quiero decir, con las condiciones mismas de su enunciación.

Primero recurro a una vinculación entre vida y escritura señalada por el mismo Parra: "Esa es una cosa que ocurrió. Yo tenía sesenta y cuatro años y ella treinta y dos. Y ella era la mujer que yo soñaba, y que yo buscaba y que creía haber encontrado... Ella era casada, tenía dos hijos... ella se suicidó. No por mí, y no en esa fecha sino que años más tarde" (Morales 1990: 142-143).

En esta línea también se puede afirmar que el corazón del hombre solo y abandonado no late imaginariamente en el texto, sino "realmente".

Dolor del corazón. Esta semántica del poema parece alejarlo radicalmente de la cueca, festiva por excelencia: "La cueca posee un carácter eminentemente festivo, y por lo tanto, no suele cantarse sólo para ser oída, sino que exige su baile, a diferencia de la tonada, que a pesar de tener con aquella correspondencias métricas, rítmicas y temáticas no se baila y sólo se canta y escucha”. La cueca es la borrachera de la música, y ningún criollo puede oírla sin sentirse ebrio de lo indefinible, escribe Joaquín Edwards Bello (Binns 2006: 930-931). No hay cueca triste, remata el autor. 


\section{LA CUECA SOLA}

Sin embargo, existe una. No solo triste, sino conmovedora: la cueca que bailaban las mujeres de detenidos desaparecidos en la época del ochenta: $L a$ cueca sola, que por cierto pertenece a la tradición chilena, pero que en esos años 80 adquiere una forma singular.

La cueca sin pareja, la cueca de la desolación y la ausencia, se empezó a bailar en teatros y plazas de Chile junto con las primeras protestas contra la dictadura, a partir del año 1983. La cueca sola es contemporánea de la escritura de "El hombre imaginario". Ambas nacen de la pérdida y el dolor. Las que bailaban públicamente eran las mujeres esposas o hijas de víctimas, muchas veces simbólicamente representadas por conjuntos de canto y baile. En "El hombre imaginario", baila el varón. El hombre que ha perdido su pareja.

Nunca el gran arte, la gran poesía, como es el caso de Nicanor Parra, es una expresión puramente individual. Siempre tiene que ver con el pueblo, "con un pueblo que falta", como afirma Deleuze. Lo que quiere decir, según el mismo autor, que la enunciación (las condiciones temporo-espaciales en que se emite el discurso) es colectiva.

Así, "El hombre imaginario", uno de los poemas más hermosos de Nicanor Parra, no puede reducirse a la metafísica, a la intemporalidad. Es un texto anclado en la historia, que coincide con un desgarro personal y colectivo. Genialmente Parra, como Cervantes, como Shakespeare, funde en un solo molde espléndido los avatares de su vida con los de su colectividad.

Por ello la "Cueca encriptada" en "El hombre imaginario" puede ser la Cueca sola. Nicanor Parra bailó y tal vez siga bailando su cueca sola en el lugar que vive, que simbólicamente se llama Las Cruces. La tentación de desarrollar estas analogías entre vida, colectividad y poesía es fuerte. Lo es, en una medida, porque el sintagrama Cueca sola está construido sobre la contradicción. Primeramente, el baile no es para moverse solo, es en pareja, es un baile "acompañado", solo excepcionalmente se baila sin acompañamiento. Por ello que hay que proponer un determinativo al baile cueca: sola. Segundo, por la oposición entre el carácter festivo de la cueca y la pena de la soledad. Tercero, porque la contradicción no es puramente negativa: la pena no logra aplastar, inmovilizar al sujeto; a pesar del dolor y la pena éste(a) baila, y en el baile da señales de vida. Parra nunca deja de efectuar su "bailecito" literal y simbólico. Unos pasitos por aquí, otros por allá, sin dejarse atrapar por críticos, lectores y por "la calva". Bailar fue una señal de vida contra la cultura de la muerte en la época militar. Si la muerte quiere inmovilizar, 
petrificar tanto el llanto como la risa, la cueca es todo lo contrario. Ella desata la pena y la alegría, hace circular los flujos de la vida, muestra que el fin de la vida no es otro que el vivirla. Por el contrario, la dictadura es adusta, corta los flujos de la libertad y el deseo. Lo hace porque teme los "contagios" de fraternidad, de caridad de igualdad. Por ello, nada más sombrío, inquisitorial que las dictaduras, encadenadas férreamente a la muerte. En Parra también hay señales de dolor, pero mitigadas por la alucinante óptica imaginaria del poema, que no solo encubre el llanto, sino otro texto dentro del mismo texto.

En la soledad de Las Cruces y al borde de los cien años, Nicanor Parra expresivamente, astutamente, sigue escobillando el suelo con su bailecito, dando señales de vida.

\section{BIBLIOGRAFÍA}

Deleuze, Gilles y Félix Guattari. El Antiedipo. Capitalismo y esquizofrenia. Paidós, 1995.

Ewards, Jorge. Diálogos en un tejado. Barcelona: Tusquets, 2003, pp. 63-64.

Morales, Leonidas. Conversaciones con Nicanor Parra. Santiago: Editorial Universitaria, 1990.

Parra, Nicanor. Obras completas \& algo + (1975-2006) vol. II. Edición establecida y anotada por Niall Binns e Ignacio Echevarría. Barcelona: Círculo de Lectores. Galaxia Gutenberg, 2011. 